\title{
Attention-deficit/hyperactivity disorder in elite athletes: a narrative review
}

\author{
Doug Hyun Han, ${ }^{1}$ David McDuff, ${ }^{\oplus, 3}$ Donald Thompson, ${ }^{4}$ Mary E Hitchcock, ${ }^{5}$ \\ Claudia L Reardon, ${ }^{6}$ Brian Hainline ${ }^{\oplus}$
}

${ }^{1}$ Department of Psychiatry,

Chung Ang University Hospital, Seoul, Republic of Korea

${ }^{2}$ Psychiatry, School of Medicine, University of Maryland, Baltimore, Maryland, USA ${ }^{3} \mathrm{MD}$ Sports Performance, Ellicott City, Maryland, USA

${ }^{4}$ School of Medicine, University of Maryland, Baltimore,

Maryland, USA

${ }^{5}$ University of WisconsinMadison, Ebling Library for the Health Sciences, Madison, WI, USA

${ }^{6}$ Department of Psychiatry, School of Medicine and Public Health, University of Wisconsin Madison, Madison, Wisconsin, USA

${ }^{7}$ National Collegiate Athletic Association (NCAA), Indianapolis, Indiana, USA

\section{Correspondence to}

Dr Doug Hyun Han, Chung Ang University Hospital, Seoul 06973, Korea (the Republic of); hduk70@gmail.com

Accepted 8 April 2019 Published Online First 8 May 2019

Check for updates

(c) Author(s) (or their employer(s)) 2019. No commercial re-use. See rights and permissions. Published by BMJ.

To cite: Han $\mathrm{DH}$,

McDuff D, Thompson D,

et al. Br I Sports Med

2019:53:741-745.

\section{ABSTRACT}

Attention-deficit/hyperactivity disorder (ADHD) is a common brain developmental disorder in the general population that may be even more prevalent in elite athletes in certain sports. General population studies of ADHD are extensive and have reported on prevalence, symptoms, therapeutic and adverse effects of treatment and new clinical and research findings. However, few studies have reported on prevalence, symptoms and treatments of ADHD in elite athletes. This narrative review summarises the literature on symptoms, comorbidities, effects of ADHD on performance and management options for elite athletes with ADHD. The prevalence of $A D H D$ in student athletes and elite athletes may be $7 \%-8 \%$. The symptoms and characteristics of ADHD play a role in athletes' choice of a sport career and further achieving elite status. Proper management of ADHD in elite athletes is important for safety and performance, and options include pharmacologic and psychosocial treatments.

\section{INTRODUCTION}

Attention-deficit/hyperactivity disorder (ADHD) is a common brain developmental disorder with a worldwide prevalence ranging from $2.5 \%$ to $7.2 \% .^{1}$ Its essential features are a persistent pattern of age-inappropriate inattention and/or hyperactivity-impulsivity causing dysfunction in multiple settings (which may include academic, work or sport settings) and interpersonal relationships since prior to the age of $12 .^{1}$

The purposes of this narrative review are to (1) synthesise the literature on the diagnosis, prevalence, effect on performance and management of ADHD in elite sport and (2) provide recommendations based on what is currently known. One of the authors ( $\mathrm{MH}$-an experienced librarian) searched key databases (PubMed, SportDiscus, PsycINFO, Scopus and Cochrane) and repeated the searches in November 2018 (3 months before intended submission). Search terms relating to $\mathrm{ADHD}$, sports participation and the elite nature of participation were combined. Reference lists of identified articles, which must have been available in English, were then used by the other authors to identify related references. Other literature was also reviewed, where there were gaps in athlete-specific literature, for guidance on diagnosis, prevalence, functional impairment and management. Elite athletes were defined as those competing at professional, Olympic or collegiate/ university levels.

\section{Diagnosis, prevalence and comorbidity of ADHD in elite athletes}

A formal diagnosis of ADHD may be made based on an athlete's symptoms and history using the criteria in the Diagnostic and Statistical Manual of Mental Disorders (DSM-5) ${ }^{2}$ (table 1). Patients with ADHD show a persistent pattern of inattention and/or hyperactivity-impulsivity that interferes with functioning or development, and includes at least 6 months of at least six symptoms from the 'inattention' or 'hyperactivity and impulsivity' category (combined type ADHD includes at least six symptoms from each of these categories). ${ }^{2}$ Additional tests that may support a diagnosis, rule out other conditions, or both, include neurocognitive and laboratory testing. In a meta-analysis, children with ADHD showed deficits of executive functions, including planning, spatial and verbal working memory, response inhibition and vigilance. ${ }^{3}$ These may be apparent and supportive of an ADHD diagnosis during neurocognitive testing of individuals suspected of having this disorder. ${ }^{3}$

Laboratory testing can help to rule out substance use, which can mimic ADHD symptoms. ${ }^{4}$ Neuroimaging as a diagnostic tool for ADHD is controversial, with inconclusive evidence to support its use, ${ }^{1}$ and protocols do not routinely recommend use of neuroimaging for this purpose. This is despite MRI studies that reveal volumetric and brain connectivity patterns associated with ADHD (table 1). Specifically, brain volumetric measurements reported volume reduction within the basal ganglia, ${ }^{5}$ cerebellum $^{6}$ and frontal lobe. ${ }^{7}$ Further, Shaw et al. demonstrated evidence of delayed rates of thinning in cortical thickness, suggesting that children with ADHD showed a delay in brain maturation. ${ }^{8}$

There are few studies regarding the prevalence of ADHD in elite athletes. Stigma against both mental health assessment and treatment among elite athletes can be strong, ${ }^{9}$ and makes it difficult to estimate the true prevalence of ADHD in elite athletes. In a meta-analysis of ADHD in adults, $30 \%$ of those diagnosed with ADHD in childhood continue to meet ADHD criteria as adults. ${ }^{910}$ Based on this rate, the prevalence of ADHD in adults may range from $0.8 \%$ to $2.4 \%$ in the general population.

ADHD may be more common in elite athletes than in the general population, since children with ADHD may be drawn to sport due to the positive reinforcing and attentional activating effects of physical activity. ${ }^{9} 11$ In a systematic review of 17 studies of ADHD, the prevalence of ADHD in athletes aged 15-19 years ranged from $4.2 \%$ to $8.1 \% .^{12}$ In Parr's observation, 50 of 701 elite athletes (7.1\%) at one 
Table 1 Clinical symptoms, neurocognitive testing findings and brain imaging findings in attention-deficit/hyperactivity disorder (ADHD)

\begin{tabular}{|c|c|}
\hline \multicolumn{2}{|l|}{ Clinical symptoms $^{2}$} \\
\hline $\begin{array}{l}\text { Inattention (note: only five or more symptoms from this category required in } \\
\text { individuals aged } \geq 17 \text { years) }\end{array}$ & Hyperactivity and impulsivity \\
\hline $\begin{array}{l}\text { Often fails to give close attention to details or makes careless mistakes } \\
\text { Often has difficulty sustaining attention in tasks or play } \\
\text { Often does not listen when spoken to directly } \\
\text { Often cannot follow through on instruction and fails to finish schoolwork, } \\
\text { chores or workplace duties } \\
\text { Often has difficulty organising tasks and activities } \\
\text { Often has difficulty engaging in tasks that require sustained mental effort } \\
\text { Often loses things } \\
\text { Often easily distracted by extraneous stimuli (in older adolescents and adults, } \\
\text { by unrelated thoughts) } \\
\text { Often forgetful in daily activities }\end{array}$ & $\begin{array}{l}\text { Often fidgets or taps hands or feet or squirms in seat } \\
\text { Often leaves seat in situations when remaining seated is expected } \\
\text { Often runs about or climbs in situations where it is inappropriate } \\
\text { Often unable to play or engage in leisure activities quietly } \\
\text { Often 'on the go', acting as if 'driven by a motor' } \\
\text { Often talks excessively } \\
\text { Often blurts out an answer before a question has been completed } \\
\text { Often has difficulty waiting for their turn } \\
\text { Often interrupts or intrudes on others }\end{array}$ \\
\hline \multicolumn{2}{|l|}{ Neurocognitive testing findings supportive of a diagnosis of ADHD ${ }^{18}$} \\
\hline Attention & Errors of omissions and commissions \\
\hline \multicolumn{2}{|l|}{ Brain imaging findings (research findings but not used for diagnostic purposes) } \\
\hline Anatomic MRI ${ }^{81}$ & $\begin{array}{l}\text { Decreased volume in basal ganglia, cerebellum, frontal, parietal and occipital lobe } \\
\text { Delayed maturation of cortex (delayed rate of cortical thinning) }\end{array}$ \\
\hline Functional MRI (fMRI) & $\begin{array}{l}\text { Decreased activity within frontobasal ganglia network, occipital, parietal and } \\
\text { temporal areas in response to motor response, interference inhibition and switching } \\
\text { task } \\
\text { Decreased activity within frontoparietal area in response to working memory task } \\
\text { Decreased synchrony between anterior and posterior parts of default mode network } \\
\text { (DMN) (resting-state fMRI) } \\
\text { Reduced anticorrelations between DMN and attention network }\end{array}$ \\
\hline
\end{tabular}

US university during the 2009-2010 academic year were taking stimulant medication for ADHD. ${ }^{13}$ Major League Baseball (MLB) in the USA annually publishes the number of players who receive a Therapeutic Use Exemption (TUE) - a process that allows athletes to request permission to take a medication that is on the World Anti-Doping Agency (WADA) Prohibited List-for stimulants prescribed for ADHD. For the 2017-2018 off-season to the end of the 2018 season, 101 players (approximately 8.4\%) were granted TUEs for ADHD. ${ }^{14}$

Of the four major American professional sports leagues (ie, MLB, National Football League, National Basketball Association and National Hockey League), only MLB publishes an annual report on TUEs. However, the $8.4 \%$ prevalence noted in the MLB 2018 annual report potentially underestimates the prevalence of ADHD in this population for at least two reasons. ${ }^{15}$ First, the clinical standards that are required to attain a TUE within the MLB policy are significantly higher than a community standard to establish a diagnosis. There are athletes who have been diagnosed and prescribed stimulants in the community who do not meet the standards of the MLB policy, and thus would be excluded from the total numbers. Second, there are athletes who have been diagnosed with ADHD, but have been treated with a non-stimulant medication or no medication, and thus would not be reported to the league's Independent Program Administrator for inclusion in the report.

Making a differential diagnosis and assessing comorbidities are important in diagnosing and managing ADHD whether in the general population or elite athletes. Conditions that might be comorbid or that might also explain ADHD-like symptoms include mood disorders (eg, major depressive and bipolar disorders), anxiety and related disorders, intellectual and learning disorders, oppositional defiant disorder, autism spectrum disorder, substance use disorders and concussion. Shared features of these diagnoses are summarised in table 2. In particular, concussion is frequently reported in athletes as a comorbidity with ADHD, with the core symptoms of poor concentration, possible deficits in memory, easy fatigue, mood fluctuation and anxiety frequently observed in both. ${ }^{16-18}$ Collegiate athletes with ADHD are more likely to report a past history of concussions than those without $\mathrm{ADHD},{ }^{19}$ and $\mathrm{ADHD}$ is associated with prolonged recovery following sport-related concussion in athletes. ${ }^{20} \mathrm{~A}$ final diagnostic consideration is that the common and normative sport-related hyperactivity seen in some athletes may be hard to distinguish from ADHD. ${ }^{21}$

\section{The negative effects of ADHD on performance and safety in elite athletes}

The symptoms of lack of focus and concentration, oppositional behaviour, argumentative attitude, frustration, lowered self-esteem and labile mood found in ADHD may impair athletic performance. $^{22}$ The neurocognitive symptoms of ADHD, including poor concentration and memory deficits, may cause academic difficulties that could threaten the academic eligibility of collegiate athletes. ${ }^{22}$ Compared with implicit (procedural) learning and implicit memory, deficits in explicit learning and explicit memory have been reported in adults with ADHD. ${ }^{23}$ Similarly, implicit learning was reported to be spared in children with ADHD. ${ }^{24}$ However, while Pedersen and Ohrmann ${ }^{25}$ have reported that adults with ADHD showed unimpaired implicit learning performance, they also showed reduced efficiency of the inhibition of incorrect response in implicit sequence learning. These results might explain why some elite athletes 
Table 2 Differential diagnosis of attention-deficit/hyperactivity disorder (ADHD) $)^{2314}$

\begin{tabular}{|c|c|c|}
\hline Disease & Shared features & Differences \\
\hline $\begin{array}{l}\text { Oppositional defiant disorder } \\
\text { (ODD) }\end{array}$ & Resisting work or school tasks & $\begin{array}{l}\text { Due to negativity, hostility and defiance (ODD) } \\
\text { Due to difficulty in sustaining mental effort, forgetting instruction and } \\
\text { impulsivity (ADHD) }\end{array}$ \\
\hline Intermittent explosive disorder (IED) & High level of impulsive behaviour & $\begin{array}{l}\text { Serious aggression towards others; no attention problems (IED) } \\
\text { Less aggression; prominent attention problems (ADHD) }\end{array}$ \\
\hline Autism Spectrum Disorder (ASD) & Dysfunctional motor behaviours & $\begin{array}{l}\text { Fixed and repetitive stereotypic movements (ASD) } \\
\text { Fidgetiness and restlessness (ADHD) }\end{array}$ \\
\hline Specific learning disorder (LD) & Learning problems & $\begin{array}{l}\text { Not impaired outside of academic work (LD) } \\
\text { Due to inattention due to frustration or lack of interest (ADHD) }\end{array}$ \\
\hline Intellectual disability (ID) & $\begin{array}{l}\text { Inappropriate and low intellectual ability in } \\
\text { academic setting }\end{array}$ & $\begin{array}{l}\text { In all other life activities (ID) } \\
\text { Not evident during non-academic tasks (ADHD) }\end{array}$ \\
\hline ASD & $\begin{array}{l}\text { Inattention, social dysfunction and behavioural } \\
\text { outbursts }\end{array}$ & $\begin{array}{l}\text { Due to inability to tolerate a change from their expected course of events (ASD) } \\
\text { Due to impulsivity or poor self-control (ADHD) }\end{array}$ \\
\hline Reactive attachment disorder (RAD) & Social disinhibition & $\begin{array}{l}\text { Lack of enduring relationships; no full ADHD symptom cluster (RAD) } \\
\text { No lack of enduring relationships; full ADHD symptom cluster (ADHD) }\end{array}$ \\
\hline Anxiety disorders (Anx) & Inattention & $\begin{array}{l}\text { Due to worry and rumination (Anx)Due to attraction to external stimuli, including } \\
\text { new or enjoyable activities (ADHD) }\end{array}$ \\
\hline $\begin{array}{l}\text { Depressive disorders } \\
\text { (Dep) }\end{array}$ & Inability to concentrate & $\begin{array}{l}\text { Prominent only during depressive episode (Dep) } \\
\text { Always present (not episodic) (ADHD) }\end{array}$ \\
\hline Bipolar disorder (BD) & $\begin{array}{l}\text { Increased activity, poor concentration and } \\
\text { impulsivity }\end{array}$ & $\begin{array}{l}\text { Accompanied by elevated mood and grandiosity occurring in episodes that last a } \\
\text { minimum of several days; rare in preadolescence (BD) } \\
\text { Significant mood change within same day (ADHD) }\end{array}$ \\
\hline Personality disorders (PD) & $\begin{array}{l}\text { Disorganisation, social intrusiveness, emotional } \\
\text { dysregulation and cognitive dysregulation }\end{array}$ & $\begin{array}{l}\text { Other clinical feature of borderline, narcissistic and other personality disorders } \\
\text { (PD) } \\
\text { No fear of abandonment, self-injury or extreme ambivalence (ADHD) }\end{array}$ \\
\hline Concussion (CC) & $\begin{array}{l}\text { Poor concentration, memory deficits and mood } \\
\text { fluctuation }\end{array}$ & $\begin{array}{l}\text { Decline in neurocognitive testing after head injury compared with baseline (CC) } \\
\text { No change of neurocognitive function in tests (ADHD) }\end{array}$ \\
\hline
\end{tabular}

make frequent and successive errors of the same type in complex sports situations.

In a study of Korean professional baseball rookies over three seasons from 2009 to 2011, elite players with a high draft ranking showed better working memory (complex attention memory) and increased brain activation in response to the Wisconsin Card Sorting Test, compared with players ranked in the lower $30 \%$ of all players drafted. ${ }^{26}$ These results suggest that elite players may employ flexible shifting via increased brain activation within the prefrontal cortex in response to complex situations, and that athletes with ADHD might be less able to use this flexible shifting. ${ }^{26}$

Additionally, commonly described comorbid conditions such as depression, anxiety and substance use disorders in ADHD may impair sports performance. ${ }^{22}$ Along with functional impairment, including that in social functioning, individuals with ADHD have a higher risk of developing mood (such as depression) and anxiety disorders. ${ }^{27} 28$ A literature review found that of ADHD, mood disorders and substance use disorders, co-occurrence of two of these disorders was commonly reported in adult athletes with ADHD. ${ }^{29}$ The impulsivity in ADHD is thought to increase the risk of substance misuse or substance use disorders. ${ }^{29}$ Overlapping symptoms between ADHD, mood, anxiety and substance use disorders may present barriers to effective diagnosis and treatment. ${ }^{30} 31$ Unstable emotions or emotional dysregulation can be one of the distinctive features of ADHD in adults, and may be misdiagnosed as a mood disorder. ${ }^{30} 31$ Most clinicians are more familiar with mood and anxiety disorders than ADHD, which can lead to misdiagnosis, underdiagnosis and undertreatment of ADHD in adult populations. ${ }^{32} 33$ Based on studies in the general population, ADHD symptoms such as impulsive and aggressive behaviours in elite athletes could be misunderstood as manifestations of substance use. ${ }^{34}$ Conversely, high stress, depressive mood and anxiety in elite athletes could manifest as a consequence of undiagnosed and untreated ADHD. ${ }^{35}$

The negative consequences of ADHD may compromise health and safety of adults with ADHD. Adults with ADHD are reported to drive cars more recklessly and have a higher incidence of traffic citations and vehicle accidents. ${ }^{36}$ In Japan, adults with ADHD were reported to visit the emergency room 10 times more than non-ADHD adults, and were hospitalised three times more than non-ADHD adults. ${ }^{37}$ Additionally, adults in Denmark with ADHD showed lower life expectancy and double the risk of death compared with non-ADHD adults. ${ }^{38}$ Thus, while the influence of ADHD on athletic performance warrants consideration, clinicians must keep in mind the substantial risks of this disorder for an individual's overall health and safety. ${ }^{25}$

\section{The positive effects of ADHD on performance in elite athletes} Common symptoms of ADHD may enhance athletic performance. Some athletes with ADHD naturally excel in baseball and basketball, which involve quick movements and reactive decision-making, due to these athletes' inherent impulsivity. ${ }^{13}$ Many children with ADHD were reported to 'hyperfocus' (highly focus) on their own enjoyable activities without being distracted by regular life activities. ${ }^{39}$ The 'hyperfocus' traits in elite athletes with ADHD may block out distractions during practice and competition. However, positive effects of ADHD in athletes have not been systemically studied. In personality studies, patients with ADHD are known to have higher scores in novelty seeking (NS). ${ }^{40}$ In a 5 -year cohort study of Korean professional baseball players, starting team members had a higher NS and reward dependence scores compared with non-starter members. ${ }^{41}$ The trait of NS was associated with impulsivity 
and hyperactivity, ${ }^{40} 42$ as well as exhilaration and excitement in response to novel stimuli or cues for potential rewards. ${ }^{42}$

ADHD may play an important role in career choice for athletes with this disorder. For example, spared implicit memory and deficits in explicit memory have been reported in adults with ADHD. ${ }^{23} 24$ Explicit learning and memory are associated with academic abilities. ${ }^{43}$ Consequently, children with ADHD may focus more on areas where they are successful, possibly including sports, since physical activity disproportionately requires implicit memory.

\section{The effects of sports and exercise on symptoms of ADHD}

Physical activity and sports may improve the symptoms of ADHD and symptoms often comorbid with ADHD, specifically inattention, depressive mood, anxiety and impaired cognition. Children with ADHD who participated in three or more sports activities were reported to have fewer anxiety and depressive symptoms, compared with those who participated in two or fewer sports activities. ${ }^{43}$ Sports participation itself can be a physical outlet for intense emotions and stress, and therefore may help reduce ADHD symptoms. ${ }^{44}$ Additionally, improved clinical symptoms of ADHD via physical activity and sports may relate to increased brain activity within the prefrontal cortex and increased brain functional connectivity from anterior to posterior brain regions. ${ }^{45} 46$ The combination of 6 weeks of aerobic exercise and methylphenidate treatment greatly increased brain activity within the prefrontal cortex in adolescents with ADHD, and improved attention and perseverative errors, compared with 6 weeks of education and methylphenidate treatment. ${ }^{45}$ Similarly, 4 weeks of equine-assisted activity and training improved inattention, gait balance and brain connectivity from frontal lobe to cerebellum in children with ADHD. ${ }^{46}$

\section{ADHD management in elite athletes}

Considerations in ADHD management include (1) symptom reduction; (2) functioning improvement (eg, social, academic, interpersonal and athletic); (3) quality of life; (4) improvement of comorbid conditions and (5) safety and tolerability of medications. ${ }^{47}$ ADHD management can be generally divided into two domains: psychosocial interventions (which include psychotherapy) and medications. In general, the consensus among sports providers is that psychosocial interventions should be the foundation of management of ADHD, with medication management if necessary. ${ }^{9}{ }^{48}$

\section{Psychological interventions}

Psychosocial interventions for ADHD must account for the age and educational level of the athlete. These interventions include behaviour therapy, cognitive behavioural therapy, individual education plans, parent teaching and training, caregiver support, mental skills training and education for athletes, families and coaches. ${ }^{11}$ Cognitive behavioural therapy in group settings include brief group therapy, ${ }^{49}$ metacognitive therapy ${ }^{50}$ and cognitive behavioural group rehabilitation. ${ }^{51}$ Dialectical behavioural group therapy consists of an interpersonal skills module, hyperactivity and disorganisation in the tolerating discomfort module, emotional instability and impulsivity in the regulation of emotions module and inattention in the mindfulness module. ${ }^{52}$ There are several reasons why psychosocial treatments for ADHD are important: (1) patients with ADHD face problems beyond ADHD's core symptoms of inattention, hyperactivity and impulsivity; (2) patients with ADHD have daily life dysfunctions in various areas including academic achievement and behaviour at school, and relationships with peers and family members and (3) these areas of dysfunction may predict poor long-term outcomes for children with ADHD. ${ }^{52}$ Psychosocial interventions provide an avenue to focus on such problems in addition to the core symptoms of ADHD. ${ }^{53}$

Psychosocial interventions may be as effective as medications in athletes with mild functional impairment ${ }^{54}$ Some clinicians recommended managing athletes with ADHD via psychosocial interventions as an alternative to medication..$^{91}{ }^{55-57}$ In a meta-analysis, psychosocial interventions were recommended as a high-value treatment for core clinical symptoms and global function in adults with ADHD. ${ }^{11485356}$

Preliminary research demonstrates that neurofeedback or electroencephalogram biofeedback may have utility for the management of ADHD symptoms in those who experienced adverse effects from medications for ADHD treatment. ${ }^{14}$ The working mechanism of neurofeedback may relate to operant conditioning theory, ${ }^{58}$ which is a method of learning with rewards and punishments for regulating behaviours. In neurofeedback, self-regulation of brain activity may be derived from operant conditioning. ${ }^{59}$ However, the biological processes at the cellular level are not understood, ${ }^{60}$ and no research on this modality has been conducted with athletes.

\section{Medication management}

Medication management for ADHD is usually divided into stimulants and non-stimulants. Stimulants (methylphenidate and amphetamine compounds) are the primary pharmacologic treatments for ADHD in the general population and in elite athletes. ${ }^{9} 21285661$ While mechanisms are not fully understood, stimulants may work via activation of dopamine and noradrenergic systems. ${ }^{61} 62$ This activation may lead to improved attention and concentration. However, these medications may also cause side effects including increased heart rate and blood pressure, abdominal pain, headache, anorexia, sleep impairment, weight loss, jitteriness and constipation. If not addressed clinically, these side effects can impair performance and/or threaten athlete safety. ${ }^{63} 64$

Overall, child and adult athletes with ADHD treated with stimulants reported better outcomes in attention to task, balance and acceleration compared with non-stimulant-treated athletes with ADHD. ${ }^{96}$ However, adult athletes with ADHD taking stimulants have also reported different side effect profiles compared with those with ADHD in the general population, including lack of creativity, lack of spontaneity, palpitations, sweating and irritability ${ }^{61}$ Additionally, prescribers must be cautious in prescribing stimulant medications if the athlete is participating in endurance events in hot temperatures because of an increased risk of heat illness. ${ }^{66}$ Stimulants appear to interfere with thermoregulation, leading to higher core temperature when exercising in hot environments. ${ }^{67} 68$ Prescribers must also be cautious if an athlete has risk factors for cardiovascular disease. ${ }^{95455}$ Sudden cardiac death has been described in elite athletes taking stimulants, possibly as a result of lowered threshold for cardiac arrhythmias. ${ }^{69}$

Sometimes, stimulants are misused by athletes because of the perception of performance enhancement. ${ }^{95} 617071$ For example, athletes who are taking stimulants may be able to exercise to higher core body temperatures without perceived thermal stress. ${ }^{68}$ Like ergogenic effects experienced with classic stimulants, the psychostimulant modafinil can mask symptoms of fatigue. ${ }^{72}$ Athletes in leanness sports (eg, distance running, gymnastics, diving and figure skating) or in sports with weight 
classes (eg, wrestling and lightweight rowing) sometimes misuse stimulants for weight loss or for a performance advantage. ${ }^{2161}$

Stimulants are prohibited by WADA in competition. ${ }^{73}$ If stimulants are prescribed for elite athletes, a TUE must be applied for and approved. ${ }^{73}$ Long-acting formulations should be considered first as they are more convenient and less likely to be misused. ${ }^{5455}$ Specifically, long-acting formulations have a slower rise and fall of stimulant levels in the brain, ${ }^{74}$ which might explain their decreased drug misuse potential. ${ }^{74}$ Short-acting formulations can be used during study periods, team meetings or film review and not during practices and competition if coaches/clinicians have concerns about safety and effects on performance. ${ }^{55561}$

A key component of the medical management of the elite athlete with ADHD who is prescribed stimulants is a close collaboration between the psychiatrist (or other prescriber), athletic trainer and primary care sports physician. Nutritionists are another important collaborator in some situations. This team approach allows for safer use of the stimulant medications while being able to monitor blood pressure, hydration and nutritional needs during both training and competition. ${ }^{54556768}$ Education and counselling around the dangers of stimulant stacking and alcohol and drug misuse while taking stimulants are also key components of the medical management of the elite athlete with ADHD. ${ }^{75}$

Another important consideration is for the involved providers to have or acquire knowledge of the sport in which the individual competes. ${ }^{15}$ Knowledge of the training and competition schedules and associated physical demands are important considerations when individualising a pharmacologic regimen. ${ }^{15}$ For example, many elite athletes may have very long days that may begin with family responsibilities in the morning hours prior to arriving at the practice or competition venue, with their sport-related work day then extending until late in the evening. Medical management of these athletes to optimise ADHD symptom control can require split dosing of a long-acting stimulant or one long-acting stimulant followed by a short-acting one with careful attention to not suppress appetite or exacerbate sleep difficulties. ${ }^{1575}$

If medications are clinically necessary for an elite athlete with ADHD, non-stimulant medications should be considered. ${ }^{215561}$ Atomoxetine may be the most recommended medication for ADHD treatments among sports psychiatrists, due to the regulatory and safety drawbacks of stimulants. ${ }^{21}$ However, atomoxetine also has side effects that limit its use, including gastrointestinal discomfort, weight loss, sedation, acute liver injury and increased suicidality. ${ }^{61}{ }^{76}$ In addition, it takes a significantly longer time (eg, 3-6 weeks) to get full benefit from atomoxetine compared with stimulants. ${ }^{132}$

Bupropion, an antidepressant with some stimulant properties via dopamine and norepinephrine reuptake inhibition, is sometimes used off-label for ADHD, ${ }^{977}$ especially for individuals with comorbid depression. In addition, the alpha-2 agonists clonidine and guanfacine in extended-release formulations are approved in some countries for use in children under the age of 18 with ADHD. ${ }^{78}$ In a systematic review and meta-analysis of 12 studies of ADHD, alpha-2 agonist monotherapy improved overall ADHD symptoms of hyperactivity, impulsivity and inattention, as well as comorbid oppositional defiant disorder symptoms. ${ }^{78}$ However, there are possible side effects, including sedation and cardiac side effects such as hypotension, bradycardia and QTc prolongation. ${ }^{78} 79$ Tricyclic antidepressants are also sometimes used as off-label medications for ADHD, ${ }^{80}$ but side effects including sedation, weight gain, cardiac arrhythmias and dry mouth may be absolute barriers for use in elite athletes. ${ }^{22}$

\section{CONCLUSION}

The symptoms and characteristics of ADHD may play a salient role in a person choosing a career in sport and competing at elite levels; the overall impact may be positive or negative. The management of ADHD in elite athletes may have important effects on safety and performance. Clinical collaboration with team physicians and athletic trainers are crucial to reduce safety concerns and to ensure the athlete does not violate antidoping rules. The focus of management should be on long-term outcomes for elite athletes in sport and life.

What is already known

- The prevalence of attention-deficit/hyperactivity disorder (ADHD) in elite athletes may be as high or higher than in the general population.

- ADHD may limit sport performance of elite athletes.

- If stimulants are prescribed for elite athletes, prescribers must be aware of the safety and tolerability issues and anti-doping rules relevant to this population.

\section{What are the new findings}

- The positive and negative aspects of ADHD may play a role in choosing a career in sports.

- Sports activity may reduce ADHD symptom frequency and severity in elite athletes.

- Psychosocial interventions may be as effective as medications to manage ADHD. These are recommended, with or without medications, for elite athletes with this disorder.

Acknowledgements The authors thank the other participants in the 2018 International Olympic Committee Consensus Meeting on Mental Health in Elite Athletes, including Cindy Miller Aron, David Baron, Antonia Baum, Abhinav Bindra, Richard Budgett, Niccolo Campriani, Joao Mauricio Castaldelli-Maia, Alan Currie, Jeff Derevensky, Lars Engebretsen, Ira Glick, Paul Filip Gorczynski, Vincent Gouttebarge, Michael Grandner, Margo Mountjoy, Aslihan Polat, Rosemary Purcell, Margot Putukian, Simon M. Rice, Allen Sills, Torbjorn Soligard, Todd Stull, Leslie Swartz and Li Jing Zhu, for their input on the development and interpretation of this research.

Contributors Authors and DHH, CLR and BH designed the current study and wrote the article. Authors DM and DT wrote the article and revised it. MEH searched for data and revised the manuscript.

Funding The authors have not declared a specific grant for this research from any funding agency in the public, commercial or not-for-profit sectors.

Competing interests None declared.

Patient consent for publication Not required.

Provenance and peer review Not commissioned; externally peer reviewed.

\section{REFERENCES}

1. Thomas R, Sanders S, Doust J, et al. Prevalence of attention-deficit/hyperactivity disorder: a systematic review and meta-analysis. Pediatrics 2015;135:e994-1001.

2. American Psychiatry Association. Diagnostic Statistical Mannual of Mental Disorders fifth ediion. Arlington, VA: American Psychiatric Assoiation, 2013.

3. Willcutt EG, Doyle AE, Nigg JT, et al. Validity of the executive function theory of attention-deficit/hyperactivity disorder: a meta-analytic review. Biological Psychiatry 2005;57:1336-46.

4. Moulahoum $\mathrm{H}$, Zihnioglu F, Timur $\mathrm{S}$, et al. Novel technologies in detection, treatment and prevention of substance use disorders. Journal of Food and Drug Analysis 2019:27:22-31.

5. Aylward EH, Reiss AL, Reader MJ, et al. Basal ganglia volumes in children with attention-deficit hyperactivity disorder. J Child Neurol 1996;11:112-5.

6. Wyciszkiewicz A, Pawlak MA, Krawiec K. Cerebellar volume in children with attentiondeficit hyperactivity disorder (ADHD). J Child Neurol 2017;32:215-21.

7. Mahone EM, Crocetti D, Ranta ME, et al. A preliminary neuroimaging study of preschool children with ADHD. The Clinical Neuropsychologist 2011;25:1009-28. 
8. Shaw P, Eckstrand K, Sharp W, et al. Attention-deficit/hyperactivity disorder is characterized by a delay in cortical maturation. Proceedings of the National Academy of Sciences 2007;104:19649-54.

9. Putukian M, Kreher JB, Coppel DB, et al. Attention deficit hyperactivity disorder and the athlete: an American medical Society for sports medicine position statement. Clinical Journal of Sport Medicine 2011:21:392-400.

10. Simon V, Czobor P, Bálint $S$, et al. Prevalence and correlates of adult attention-deficit hyperactivity disorder: meta-analysis. Br J Psychiatry 2009;194:204-11.

11. Wolraich M, Brown L, Brown RT, et al. ADHD: clinical practice guideline for the diagnosis, evaluation, and treatment of attention-deficit/hyperactivity disorder in children and adolescents. Pediatrics 2011;128:1007-22.

12. Poysophon $P$, Rao AL. Neurocognitive deficits associated with ADHD in athletes: a systematic review. Sports Health 2018;10:317-26.

13. Parr JW. Attention-deficit hyperactivity disorder and the athlete: new advances and understanding. Clin Sports Med 2011;30:591-610.

14. Martin T. Public Report of Major League Baseball's Joint Drug Prevention and Treatment Program, 2018. Available: http://www.mlb.com/documents/3/8/2/ 301315382/IPA_2018_Public_Report_113018.pdf [Accessed 31 Jan 2019].

15. McDuff DR, Garvin M. Working with sports organizations and teams. International Review of Psychiatry 2016;28:595-605.

16. Harmon KG, Drezner JA, Gammons M, et al. American medical Society for sports medicine position statement: concussion in sport. Br J Sports Med 2013;47:15-26.

17. Nelson LD, Guskiewicz KM, Marshall SW, et al. Multiple self-reported concussions are more prevalent in athletes with ADHD and learning disability. Clinical Journal of Sport Medicine 2016;26:120-7

18. Williams WH, Potter S, Ryland H. Mild traumatic brain injury and Postconcussion syndrome: a neuropsychological perspective. Journal of Neurology, Neurosurgery \& Psychiatry 2010:81:1116-22.

19. McCrory P, Meeuwisse W, Johnston K, et al. Consensus statement on concussion in sport 3rd international Conference on concussion in sport held in Zurich, November 2008. Clinical Journal of Sport Medicine 2009;19:185-200.

20. Esfandiari A, Broshek DK, Freeman JR. Psychiatric and neuropsychological issues in sports medicine. Clin Sports Med 2011;30:611-27.

21. Reardon CL, Factor RM. Considerations in the use of stimulants in sport. Sports Med 2016:46:611-7

22. White RD, Harris GD, Gibson ME. Attention deficit hyperactivity disorder and athletes. Sports Health 2014;6:149-56.

23. Pollak Y, Kahana-Vax G, Hoofien D. Retrieval processes in adults with ADHD: a RAVLT study. Developmental Neuropsychology 2007:33:62-73.

24. Takács Ádám, Shilon Y, Janacsek K, et al. Procedural learning in Tourette syndrome, ADHD, and comorbid Tourette-ADHD: evidence from a probabilistic sequence learning task. Brain and Cognition 2017;117:33-40.

25. Pedersen A, Ohrmann P. Impaired behavioral inhibition in implicit sequence learning in adult ADHD. J Atten Disord 2018;22:250-60.

26. Han D, Kim B, Cheong J, et al. Anxiety and attention shifting in professional baseball players. Int J Sports Med 2014;35:708-13.

27. Ginsberg Y, Hirvikoski T, Lindefors N. Attention deficit hyperactivity disorder (ADHD) among longer-term prison inmates is a prevalent, persistent and disabling disorder. BMC Psychiatry 2010;10

28. Spencer T, Biederman J, Wilens T, et al. A large, double-blind, randomized clinical trial of methylphenidate in the treatment of adults with attention-deficit/hyperactivity disorder. Biological Psychiatry 2005;57:456-63.

29. Regnart J, Truter I, Meyer A. Critical exploration of co-occurring attention-deficit/ hyperactivity disorder, mood disorder and substance use disorder. Expert Review of Pharmacoeconomics \& Outcomes Research 2017:17:275-82.

30. Barkley RA, Brown TE. Unrecognized attention-deficit/hyperactivity disorder in adults presenting with other psychiatric disorders. CNS Spectr 2008;13:977-84.

31. Rösler M, Retz W, Fischer R, et al. Twenty-four-week treatment with extended release methylphenidate improves emotional symptoms in adult ADHD. The World Journal of Biological Psychiatry 2010;11:709-18.

32. McIntosh D, Kutcher S, Binder C, et al. Adult ADHD and comorbid depression: a consensus-derived diagnostic algorithm for ADHD. Neuropsychiatr Dis Treat 2009:5:137-50.

33. Caye A, Rocha TB, Anselmi L, et al. Attention-deficit/hyperactivity disorder trajectories from childhood to young adulthood: evidence from a birth cohort supporting a lateonset syndrome. JAMA psychiatry 2016;73:705-12.

34. Agnew-Blais JC, Polanczyk GV, Danese A, et al. Evaluation of the persistence, remission, and emergence of attention-deficit/hyperactivity disorder in young adulthood. JAMA Psychiatry 2016;73:713-20.

35. Alexander SJ, Harrison AG. Cognitive responses to stress, depression, and anxiety and their relationship to ADHD symptoms in first year psychology students. J Atten Disord 2013;17:29-37.

36. Barkley RA, Murphy KR, Dupaul Gl, et al. Driving in young adults with attention deficit hyperactivity disorder: knowledge, performance, adverse outcomes, and the role of executive functioning. J Int Neuropsychol Soc 2002;8:655-72.

37. Kirino E, Imagawa H, Goto T, et al. Sociodemographics, comorbidities, healthcare utilization and work productivity in Japanese patients with adult ADHD. Plos One 2015; 10:e0132233.
38. Dalsgaard S, Østergaard SD, Leckman JF, et al. Mortality in children, adolescents, and adults with attention deficit hyperactivity disorder: a nationwide cohort study. The Lancet 2015;385:2190-6.

39. Hupfeld KE, Abagis TR, Shah P. Living "in the zone": hyperfocus in adult ADHD. ADHD Atten Def Hyp Disord. In Press 2018;23.

40. Perroud N, Hasler R, Golay N, et al. Personality profiles in adults with attention deficit hyperactivity disorder (ADHD). BMC Psychiatry 2016;16.

41. Kang KD, Han DH, Hannon JC, et al. Temperamental predictive factors for success in Korean professional baseball players. Psychiatry Investig 2015;12:459-65.

42. Cloninger CR. A systematic method for clinical description and classification of personality variants. Arch Gen Psychiatry 1987;44:573-88.

43. Kiluk BD, Weden S, Culotta VP. Sport participation and anxiety in children with ADHD. J Atten Disord 2009;12(6):499-506. 43. Vierkant T. Self-knowledge and knowing other minds: the implicit/explicit distinction as a tool in understanding theory of mind. Br J Dev Psychol 2012;30:141-55.

44. McKune AJ, Pautz J, Lomjbard J. Behavioural response to exercise in children with attention-deficit/hyperactivity disorder. S. Afr. j. sports med. 2003;15:17-21.

45. CHOI JAEWON, Han DH, KANG KDOO, et al. Aerobic exercise and attention deficit hyperactivity disorder. Medicine \& Science in Sports \& Exercise 2015;47:33-9.

46. Hyun GJ, Jung T-W, Park JH, et al. Changes in gait balance and brain connectivity in response to Equine-Assisted activity and training in children with attention deficit hyperactivity disorder. The Journal of Alternative and Complementary Medicine 2016:22:286-93

47. Katzman MA, Bilkey TS, Chokka PR, et al. Adult ADHD and comorbid disorders: clinica implications of a dimensional approach. BMC Psychiatry 2017;17.

48. Seixas M, Weiss M, Müller U. Systematic review of national and international guidelines on attention-deficit hyperactivity disorder. J Psychopharmacol 2012:26:753-65.

49. Wiggins $D$, Singh $K$, Getz HG, et al. Effects of brief group intervention for adults with attention defi cit/hyperactivity disorder. J Ment Health Couns 1999;21:82-93.

50. Solanto MV, Marks DJ, Mitchell KJ, et al. Development of a new psychosocial treatment for adult ADHD. Journal of Attention Disorders 2008;11:728-36.

51. Virta M, Vedenpaa A, Gronroos N, et al. Adults with ADHD benefit from cognitivebehaviorally oriented group rehabilitation: a study of 29 participants. J Atten Disord 2008:12:218-26.

52. Hesslinger $B$, Tebartz van Elst $L$, Nyberg E, et al. Psychotherapy of attention deficit hyperactivity disorder in adults-a pilot study using a structured skills training program. Eur Arch Psychiatry Clin Neurosci 2002;252:177-84.

53. López-Pinar C, Martínez-Sanchís S, Carbonell-Vayá E, et al. Long-term efficacy of psychosocial treatments for adults with attention-deficit/hyperactivity disorder: a meta-analytic review. Front. Psychol. 2018;9.

54. Reardon CL, Creado S. Psychiatric medication preferences of sports psychiatrists. The Physician and Sportsmedicine 2016:44:397-402.

55. Perrin $A E$, Jotwani VM. Addressing the unique issues of student athletes with ADHD. J Fam Pract 2014;63:E1-9.

56. Stewman CG, Liebman C, Fink L, et al. Attention deficit hyperactivity disorder: unique considerations in athletes. Sports Health 2018;10:40-6.

57. Pelham WE, Burrows-Maclean L, Gnagy EM, et al. Transdermal methylphenidate, behavioral, and combined treatment for children with ADHD. Exp Clin Psychopharmacol 2005:13:111-26.

58. Heinrich H, Gevensleben H, Strehl U. Annotation: Neurofeedback ? train your brain to train behaviour. J Child Psychol \& Psychiat 2007;48:3-16.

59. Strehl U. What learning theories can teach us in designing neurofeedback treatments. Front. Hum. Neurosci. 2014;8.

60. Razoki B. Neurofeedback versus psychostimulants in the treatment of children and adolescents with attention-deficit/hyperactivity disorder: a systematic review. Neuropsychiatr Dis Treat 2018;14:2905-13.

61. Conant-Norville DO, Tofler IR. Attention deficit/hyperactivity disorder and psychopharmacologic treatments in the athlete. Clin Sports Med 2005:24:829-43.

62. Del Campo N, Chamberlain SR, Sahakian BJ, et al. The roles of dopamine and noradrenaline in the pathophysiology and treatment of attention-deficit/hyperactivity disorder. Biol Psychiatry 2011;69:e145-57.

63. Hamilton RM, Rosenthal E, Hulpke-Wette M, et al. Cardiovascular considerations of attention deficit hyperactivity disorder medications: a report of the European Network on hyperactivity disorders work group, European attention deficit hyperactivity disorder guidelines group on attention deficit hyperactivity disorder drug safety meeting. Cardiol Young 2012;22:63-70

64. Bezchlibnyk-Butler KZ, Jeffries JJ, Procyshyn RM. Clinical Handbook of Psychotropic Drugs: Hogrefe Publishing, 2012.

65. Pelham WE, McBurnett K, Harper GW, et al. Methylphenidate and baseball playing in ADHD children: who's on first? Journal of Consulting and Clinical Psychology 1990:58:130-3.

66. Howe AS, Boden BP. Heat-related illness in athletes. Am J Sports Med 2007:35:1384-95.

67. May DE, Kratochvil CJ. Attention-deficit hyperactivity disorder: recent advances in paediatric pharmacotherapy. Drugs 2010;70:15-40.

68. Roelands $\mathrm{B}$, Hasegawa $\mathrm{H}$, Watson $\mathrm{P}$, et al. The effects of acute dopamine reuptake inhibition on performance. Medicine \& Science in Sports \& Exercise 2008;40:879-85. 
69. Drezner JA, O'Connor FG, Harmon KG, et al. AMSSM position statement on cardiovascular Preparticipation screening in athletes: current evidence, knowledge gaps, recommendations, and future directions. Clin I Sport Med 2016;26:347-61.

70. Veliz P, Boyd C, McCabe SE. Adolescent athletic participation and nonmedical Adderall use: an exploratory analysis of a performance-enhancing drug. J. Stud. Alcohol Drugs 2013;74:714-9.

71. Greydanus DE, Patel DR. Sports doping in the adolescent athlete the hope, hype, and hyperbole. Pediatr Clinics North Am 2002;49:829-55.

72. Jacobs IRA, Bell DG. Effects of acute modafinil ingestion on exercise time to exhaustion. Medicine \& Science in Sports \& Exercise 2004;36:1078-82.

73. World anti-doping agency (Wada) world anti-doping agency Prohibited list 2019Prohibited list 2019, 2019. Available: https://www.usada.org/substances/ prohibited-list/

74. Swanson J, Gupta S, Lam A, et al. Development of a new once-a-day formulation of methylphenidate for the treatment of attention-deficit/hyperactivity disorder: proof-ofconcept and proof-of-product studies. Arch Gen Psychiatry 2003;60:204-11.

75. McDuff D. Substance Use and Abuse. In: McDuff D, ed. Sports psychiatry: strategies for life balance and peak performance 1st ED, pp.175-179. Washington, DC: American Psychiatric Publishing, 2012.
76. Bushe CJ, Savill NC. Systematic review of atomoxetine data in childhood and adolescent attention-deficit hyperactivity disorder 2009-2011: focus on clinical efficacy and safety. J Psychopharmacol 2014;28:204-11.

77. Verbeeck W, Bekkering GE, Van den Noortgate W, et al. Bupropion for attention deficit hyperactivity disorder (ADHD) in adults. Cochrane Database Syst Rev 2017;52.

78. Hirota T, Schwartz S, Correll CU. Alpha-2 agonists for attention-deficit/hyperactivity disorder in youth: a systematic review and meta-analysis of monotherapy and add-on trials to stimulant therapy. Journal of the American Academy of Child \& Adolescent Psychiatry 2014;53:153-73.

79. Joo SW, Kim H-W. Treatment of children and adolescents with attention deficit hyperactivity disorder and/or Tourette's disorder with clonidine extended release. Psychiatry Investig 2018;15:90-3.

80. Pujalte GGA, Maynard JR, Thurston MJ, et al. Considerations in the care of athletes with attention deficit hyperactivity disorder. Clinical Journal of Sport Medicine 2017.

81. Mitelman SA. Transdiagnostic neuroimaging in psychiatry: a review. Psychiatry Res. In Press 2019. 